\title{
The use of hybrid aeration system in wastewater treatment
}

\author{
Mohammed Salim Shihab \\ Mosul University, Engineering College, Environmental Engineering Department
}

Rec. 14 Aug, 2011 Accpt. 21 Sep, 2011

\begin{abstract}
The objective of this study was to demonstrate and assess the effectiveness of hybrid aeration system and to identify how equipment improvements and operational adjustments will impact the efficiency of the aeration process. Evaluating of oxygen transfer rate and oxygenation capacity were the functions to assess such system's efficiency. Periodical runs, with enhancement of two laboratory glass basin model with (58) liter for each were conducted, one was for water and the other for wastewater where D.O analysis were taken stimulatingly at peered time intervals. Speed mixing and air discharge were the main parameters that used in detecting system efficiency. The study showed that the best result was obtained at air discharge about ( $1490 \mathrm{ml} / \mathrm{min}$. ) and mixer (50 RPM), that alpha factor and oxygenation capacity were (1.12) and (43.2 $\mathrm{mg} \mathrm{O}_{2} / \mathrm{L}$. min.), respectively. However, the study concluded that increasing mixing speed and air discharge may affect conversely on bubble size and consequently on oxygen transfer rate in aeration systems of wastewater treatment plant.
\end{abstract}

Keywords: Oxygen transfer, Hybrid Aeration, Alpha factor, Aeration Systems.

\section{Introduction}

The requirements to improve effluent quality have led to the establishment of better design procedures for activatedsludge plants. Aeration process in most wastewater treatment plant consumes a major portion of plant's power, thus, the aeration systems represent the impact factor in designing an economical and efficient operated plant (Smith, 2001).

Although there are many types of aeration systems, the two basic methods of aerating wastewater are through mechanical surface aeration to entrain air into the wastewater by agitation, or by introducing air or pure oxygen with submerged diffusers. Finebubble diffused-air techniques are potentially more efficient than mechanical surfaceaeration systems, but low oxygen-transfer efficiency is often observed in practice under conditions of high aeration tank solids loading. Conversely, surface-aeration systems appear to be able to operate at reasonable aeration efficiencies under conditions of high loading, but they are not as effective as diffused-air systems in lowrate processes (Chambers et al., 1998).

The focus of this paper was to assess a simple baseline model of a municipal wastewater treatment of aeration system's facilities, in order to understand the various operational strategies and equipments selection in wastewater treatment. As part of the calculation process of comparing aeration system equipments, the relative rate of oxygen transfer in wastewater compared to clean water must be established (alpha value).

\begin{tabular}{|c|c|}
\hline Aeration System & Typical Alpha $(\alpha)$ \\
\hline Course Bubble Diffusers & 0.80 \\
\hline Fine Bubble Diffusers & 0.45 \\
\hline Jet Aeration & 0.75 \\
\hline $\begin{array}{c}\text { Surface Mechanical } \\
\text { Aerators }\end{array}$ & 0.85 \\
\hline Submerged Turbines & 0.85 \\
\hline
\end{tabular}

Table. (1): Typical Alpha Values (USEPA, 1989).

Another important function of the aeration equipment is to provide adequate mixing in the tanks to prevent solids from settling. It is typical for many municipal wastewater treatment facilities to have BOD load to be the predominant factor for the aeration system to satisfy during the day, but when BOD loads decrease during the late evening hours, adequate mixing in the tank may be the controlling energy requirement. Table 2. Shows typical minimum mixing values for aeration tanks (USEPA, 1989; Metcalf and Eddy, 2003).

\footnotetext{
* Corresponding author:

Dr. Mohammed Salim Shihab

凶mohammed_19772000@yahoo.com
} 


\begin{tabular}{|c|c|}
\hline $\begin{array}{c}\text { Type of Aeration } \\
\text { System }\end{array}$ & $\begin{array}{c}\text { Mixing } \\
\text { Requirement }\end{array}$ \\
\hline Course Bubble & 20 to $30 \mathrm{scfm} / 1000$ \\
Diffused Aeration & cu.ft. \\
\hline $\begin{array}{c}\text { Fine Bubble Diffused } \\
\text { Aeration }\end{array}$ & $\begin{array}{c}7 \text { to } 10 \mathrm{scfm} / 1000 \\
\text { cu.ft. }\end{array}$ \\
\hline $\begin{array}{c}\text { Mechanical Surface } \\
\text { Aeration }\end{array}$ & $\begin{array}{c}0.6 \text { to } 1.15 \mathrm{hp} / 1000 \\
\text { cu.ft. }\end{array}$ \\
\hline
\end{tabular}

Table. (2): Typical Aeration Tank Mixing Requirement.

For most aeration designs alpha factor used in many fine bubble activated sludge systems is as low as 0.5 ; this results in a process aeration efficiency (PAE) that is already reduced to half of the clean-water efficiency (Smith, 2001).

EPA conducted a study depending on the place of using aeration equipment in plug flow reactor. The study comes out with that when using fine bubble aeration alpha value was 0.3 at reactor influent while it was 0.8 at effluent.

In survey study conducted by (Chambers et al., 1998). the activated-sludge plants using hybrid aeration systems at Whitlingham, Blackburn Meadows and Wanlip produce consistently good effluent quality (measured in terms of BOD, SS and $\mathrm{NH}_{3}$ ). The aeration efficiency of the plants varies between 1.0 and $1.4 \mathrm{~kg} / \mathrm{kWh}$ and depends upon the assumptions used in design being reflected in actual sewage characteristics and operating conditions. The installation of FBDA (Fine Bubble Diffused Aeration) equipment in relatively low-loaded regions of the aeration tanks does not result in diffuser sliming or blockage with consequent performance deterioration.

A model for oxygen transfer rate in diffused air systems was proposed by (Bayramoglu et al., 2000). The model parameters were found by means of non linear regression analysis, using plant data given in the literature. The proposed model may be useful for the preliminary design of diffused air aeration tanks.

In order to optimize aeration in the activated sludge processes, an experimentally validated numerical tool was proposed by (Yannick, 2007). based on computational fluid dynamics and able to predict flow and oxygen transfer characteristics in aeration tanks equipped with fine bubble diffusers and axial slow speed mixers. For four different aeration tanks $\left(1 ; 1493 ; 8191\right.$ and $\left.29.313 \mathrm{~m}^{3}\right)$. Predicted oxygen transfer coefficients were within $\pm 5 \%$ of experimental results that ranged from $\left(2.19 \times 10^{3}-1.71 \times 10^{3} \mathrm{~s}^{-1}\right)$ for different operating conditions (varying pumping flow rates of the mixers and air flow rates).

The effect of airflow rate and the level of diffusers submergence, on the oxygen transfer rate of diffused air systems was determined by (Al-Ahmady, 2006). He derived an individual mathematical models to describe the effect of each parameter. The results of the study showed that, increasing the airflow rate at fixed water depth and diffusers submergence enlarge the oxygenation capacity of the system. The equation, which controls this relationship, is linear. At diffusers submergence of $4.6 \mathrm{~m}$, the slope of the equation was 11.8. With reduce the depth of diffusers to about $0.4 \mathrm{~m}$; the slope of equation was decrease to 2.3. At constant airflow rate, the depth of diffusers has a significant effect on both of the oxygenation capacity and the oxygen transfer efficiency of the system. Exponential form of equation is shown to be efficient in expressing the relationship between the submergence and the oxygenation capacity. At $0.4 \mathrm{~m}$, diffusers submergence, the oxygen transfer efficiency was 1.8 whereas; this value is increased to about 11.5 at $4.6 \mathrm{~m}$ submergence.

(Zhen $\mathrm{He}$ et al., 2003). measures the oxygen transfer capacity in clean water by using desorption and absorption techniques. For the absorption method, the mean value of $\mathrm{KLa}_{20}$ was obtained as $8.60 \mathrm{~h}^{-1}$ with a water volume of 14L. Meanwhile, standard oxygen transfer efficiency (SOTE) was shown in the range of $4.5-4.9 \%$ with water depth 0.3 $\mathrm{m}$ by correcting the airflow condition. Desorption measurement was investigated to certify the influence of water depth on SOTE. Five different water depths $(0.24$, $0.26,0.27,0.30$, and $0.32 \mathrm{~m}$ ) are chosen as test objective. Due to the small interval of water depths chosen in this experiment, it was difficult to measure the exact change of SOTE with water depth. However, SOTE increased with the water depth. 


\section{Experimental Work}

According to (Pre-European Standards, 1999). Oxygen transfer information was obtained by using laboratory (bench-scale) apparatus. All tests reported herein were carried out by using two equally laboratory scale tanks $(0.55 \mathrm{~m} \times 0.40 \mathrm{~m} \times 0.35 \mathrm{~m})$, as shown in figure (1), which were operated in the batch mode. The DO probe was installed at half water depth for absorption measurement. Within the tank, the diffusers were placed $10 \mathrm{~cm}$ from the tank's bottom. Prior to each group of runs, the tanks were drained, cleaned and filled with clean water to avoid salt accumulation. The experiment program was divided into four groups. In each group, the effect of air discharge and mixing intensity, on the studied parameters were investigated as shown in table (3).

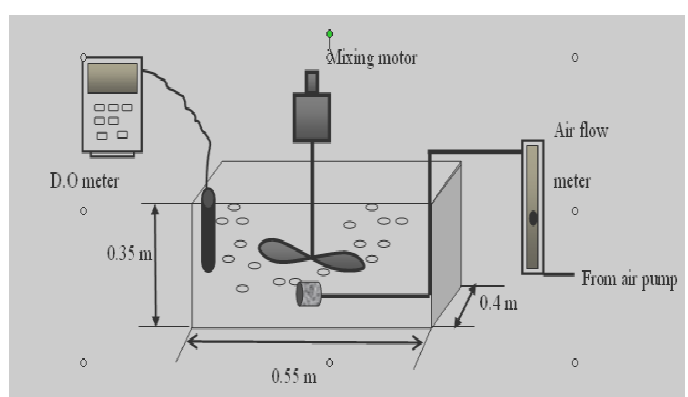

Fig. 1: Configuration of the experimental work.

Table (3) below shows the experiment design accordingly to the experiment specification group which coincided mixing intensity and air flowrate in both water and wastewater basins model.

\begin{tabular}{|c|c|c|c|}
\hline Sample type & $\begin{array}{c}\text { Group } \\
\text { No. }\end{array}$ & $\begin{array}{c}\text { Air } \\
\text { discharge } \\
\left(\mathbf{m}^{\mathbf{3}} \text { / day }\right)\end{array}$ & $\begin{array}{c}\text { Mixing } \\
\text { intensity } \\
\text { ( RPM })\end{array}$ \\
\hline \multirow{3}{*}{ Tap water } & 1 & 5.35 & 50 \\
\cline { 2 - 4 } & 2 & 5.35 & 100 \\
\cline { 2 - 4 } & 3 & 10.7 & 50 \\
\cline { 2 - 4 } & 4 & 10.7 & 100 \\
\hline \multirow{3}{*}{ Wastewater } & 1 & 5.35 & 50 \\
\cline { 2 - 4 } & 2 & 5.35 & 100 \\
\cline { 2 - 4 } & 3 & 10.7 & 50 \\
\cline { 2 - 4 } & 4 & 10.7 & 100 \\
\hline
\end{tabular}

Table. (3): Demonstration of Experiments Design.

The major shortage in these tests that they were carried out in small scale so, their results mainly limits by the test circumstances.

\section{Calibration of DO Probe}

Calibration of DO probe (EXTECH; model 407510) is necessary for the precise measurement. The methods used in this experiment consist of zero check and saturation check. The zero check was run every time after the probe was turned on, by putting probe into a $1 \mathrm{~L}$ cylindrical glass added by $1 \mathrm{~g}$ sodium sulfate and 1 mg cobalt. With excess chemical, the water in the tube should contain zero dissolved oxygen. Saturation check was done before and after measurement, according to the operation manual for the probe.

\section{Temperature Measurement}

The temperature of test water was read from the DO meter. The variation of temperature should be with an accuracy of $\pm 0.5{ }^{\circ} \mathrm{C}$ at the beginning and the end of each test (German ATV Standards ,1996).

KLaT was determined by evaluation of an oxygen transfer test in clean water and wastewater at a certain aeration setting and at a certain temperature. So, it was converted to the standard temperature of $\mathrm{T}=20{ }^{\circ} \mathrm{C}$ as follows (Metcalf and Eddy ,2003):

$(\mathrm{KLa}) \mathrm{T}=(\mathrm{KLa})_{20} \times(\theta)^{\mathrm{T}-20}$

Where:

$(\mathrm{KLa})_{20}=$ value of $\mathrm{KLa}$ at $20^{\circ} \mathrm{C}$.

$(\mathrm{KLa}) \mathrm{T}=$ value of $\mathrm{KLa}$ at test water temperature.

$\mathrm{T}=$ test water temperature, ${ }^{\circ} \mathrm{C}$.

$\theta=1.024$

\section{Airflow Rate Measurement}

A laboratory flow meter was used to measure the airflow rate. The accuracy of the flow meter has been checked before application. The inverse measuring cylinder filled with water was used to calibrate air flowrate. The airflow of $1490 \mathrm{ml} / \mathrm{min}$ and $2980 \mathrm{ml} / \mathrm{min}$. was applied in the measurement.

The oxygen transfer tests were conducted in parallel using tap water and domestic wastewater for comparative purposes and deducing the correction factor of Oxygen transfer coefficient. There are several methods of experimental determination of mass transfer coefficients. The so-called clean water non-steady state method was selected in this study. The unsteady state test 
is presently the most broadly accepted test procedure .This method was practiced according to the procedure advised by (Eckenfelder, 2000; Ramalho, 1977). which involves.:

1. Removing the dissolved oxygen in the aeration tank by adding sodium sulfate $\mathrm{Na}_{2} \mathrm{SO}_{3} \quad(8 \mathrm{mg} / \mathrm{l}$ per $1 \mathrm{mg} / \mathrm{l}$ of dissolved oxygen) and cobalt chloride $\left(\mathrm{CoCl}_{2} \cdot 6 \mathrm{H}_{2} \mathrm{O}\right)$ concentration of $0.05 \mathrm{mg} / 1$ to provide a minimum $\mathrm{Co}^{+2}$ of $1.5 \mathrm{mg} / 1$.

2. Thoroughly mix the tank contents.

3. Recording of the oxygen concentration increase while aerating the previously deoxygenated water.

4. Recording the temperature and measuring oxygen saturation value from tables (Metcalf and Eddy, 2003).

5. Computing the oxygen transfer rate in accordance to Eq. (2) as shown below.

It makes no difference to aerate with air or with oxygen because the value of oxygen transfer coefficient $(\mathrm{KL})$ is only dependent on the hydrodynamic properties of the system (Metcalf \& Eddy, 2003). Relationships that describe the rate of water oxygenating in step (3), and formula for computing the oxygen mass transfer coefficient are presented in the following:

$\frac{d c}{d t}=K L a(C s w-C L)$

Where:

$\mathrm{dc} / \mathrm{dt}$ : the rate of change of the oxygen concentration

KLa: oxygen transfer rate across the gas liquid film, (1/min.)

$\mathrm{CL}$ : oxygen concentration at time $(\mathrm{t}),(\mathrm{mg} / \mathrm{L})$

Csw: the saturation concentration of oxygen in water and wastewater, $(\mathrm{mg} / \mathrm{L})$

$\mathrm{t}$ : the time, (min.)

The representation of eq. (2) was depicted in fig (2), showing the determination of KLa.

The difference (Csw, - CL) between saturation value and actual concentration of oxygen (CL) in the body of the liquid phase is usually called oxygen deficit. The oxygen transfer rate was determined by integrating of this equation.

From equation (2), the initial oxygen uptake rate at $\mathrm{CL}=0$, is

$\frac{d c}{d t}=\mathrm{OC}=K L a(C s w)$

Where:

$O C=$ the oxygen transfer capacity of the system, $\left(\mathrm{grO}_{2} / \mathrm{m}^{3}\right.$ water. $\left.\mathrm{hr}\right)$
To introduce the effect of wastewater on the results obtained from this procedure, the following equation for admixtures correction factor is usually used (Kalinske et al., 1973). $\alpha=\frac{\text { KLa wastewater }}{\text { KLawater }}$

Where:

$\mathrm{KLa}=$ Oxygen transfer coefficient for the specific admixture $(1 / \mathrm{hr})$.

$\alpha=$ the admixtures correction factor.
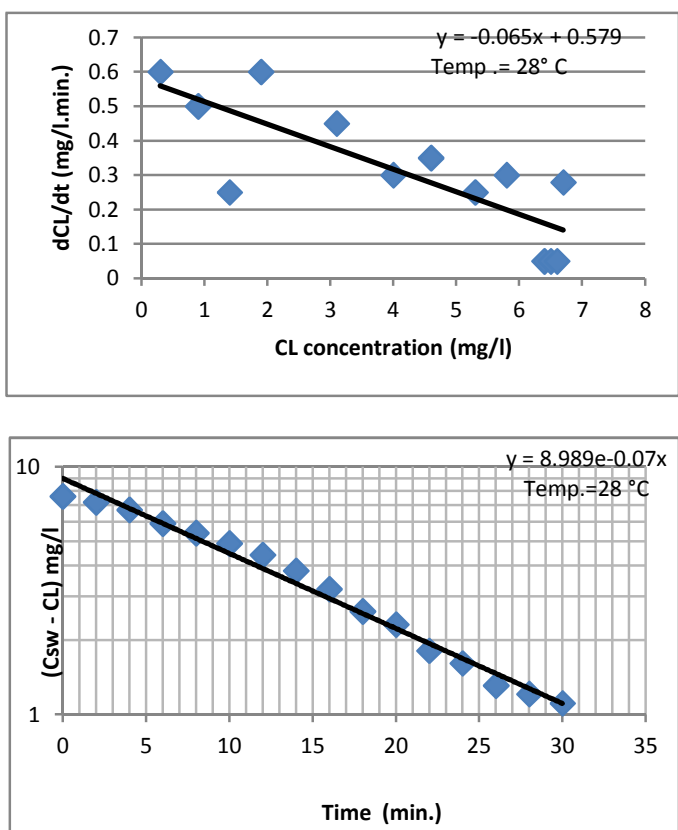

Fig. 2: Sample of the experimental results depicting oxygen transfer coefficient determination for (A-water and B-wastewater).

In table (4), the values of correction factor for some types of wastewater are represented.

\begin{tabular}{|c|c|}
\hline Type of Wastewater & $\alpha-$ factor \\
\hline Domestic wastewater & 0.85 \\
\hline Dairy wastewater & 0.82 \\
\hline $\begin{array}{c}\text { Wastewater from chemicals } \\
\text { industries }\end{array}$ & 0.7 \\
\hline $\begin{array}{c}\text { Pulp and paper industry } \\
\text { wastewater }\end{array}$ & 0.7 \\
\hline $\begin{array}{c}\text { Wastewater from acidic } \\
\text { industries }\end{array}$ & 0.5 \\
\hline
\end{tabular}

Table. ( 4): Values of The Correction Factor for Some Types of Wastewater (Khudenko and Shpirt , 1986).

\section{Results and Discussion:}

Fig. (3). depicted the effect of mixing intensity and air flowrate on oxygen transfer rate (KLa) for both water and wastewater samples. Obviously, mixing intensity and air flowrate (group No.2 and 4) have noticeable 
effect on such factor that increasing mixing intensity to $100 \mathrm{RPM}$ increased (KLa of water sample) from 1.5 to $2.88 \mathrm{hr}^{-1}$ at fixed air flowrate $5.35 \mathrm{~m}^{3} /$ day, while duplicating air flowrate to $10.7 \mathrm{~m}^{3} /$ day increased (KLa) from 2.88 to $3.42 \mathrm{hr}^{-1}$ at $100 \mathrm{RPM}$. It seemed that mixing intensity were more effected than air flowrate on (KLa), about $48 \%$ increment. Conversely, air flowrate increment was decreased $(\mathrm{K} \quad \mathrm{La})$ of wastewater sample from 2.1 to1.8 $\mathrm{hr}^{-1}$ at 100RPM, about 85\%, (see table 5). Practically, it was shown that the presence of certain organic chemicals (surfactants) was increased resistance at the gas/liquid interface, which impedes molecular diffusion, D, and forms rigid surface on bubbles that reduced the liquid film coefficient $\mathrm{KL}$ and overall mass transfer coefficient, $\mathrm{KLa}$, to about $55 \%$ depending on type of surfactant, concentration and type of wastewater (Shifrin etal,1977; Wagner and Johannes, 1986).

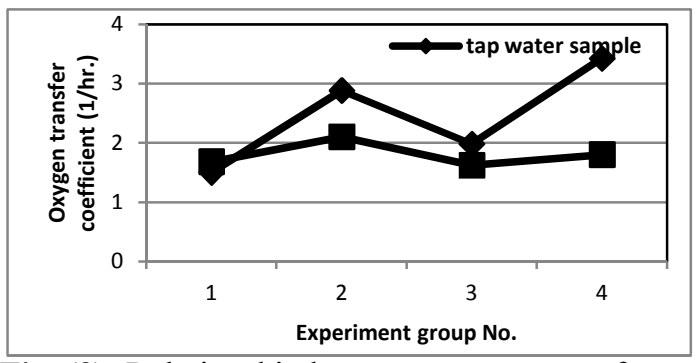

Fig. (3): Relationship between oxygen transfer rate with mixing intensity and air flowrate

Since, the major component in wastewater effecting $\mathrm{KLa}$ in fig (3). was surfactants which was a highly significant impact on the gas-liquid interface, decreasing the surface tension of the interface and making transfer more difficult, which increased as the bubble size gets smaller (Mark,2005) So , fine bubble diffusers have adverse effect on Oxygen correction factor $(\alpha)$. While, in activated sludge systems using mechanical aerators, surfactants help in producing smaller water droplets, increasing the available surface area for oxygen transfer. Thus, the alpha factor can actually be above1.0 (Smith, 2001). Basically, oxygen correction factor $(\alpha)$ depends on KLa coefficient, group (1) that had low mixing intensity of 50 RPM and air flowrate 5.35 $\mathrm{m}^{3} /$ day, which produced relatively large bubble size, gave the best results for this factor about (1.12) as depicted in fig (4).

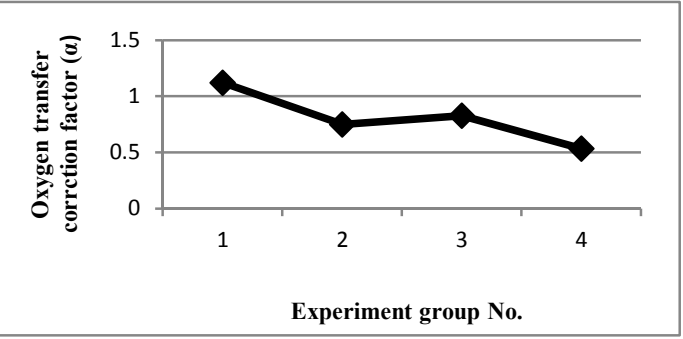

Fig. (4): Relationship between oxygen transfer correction factor with mixing intensity and air flowrate

Furthermore, fig (5) demonstrates the effect of studied parameter on oxygenation capacity (OC). Since oxygenation capacity was related to oxygen transfer coefficient, its obviously that group (1) was the dominating factor for this parameter. Oxygenation capacity was $43.22 \mathrm{mg} \mathrm{O}_{2} / \mathrm{min}$ for wastewater, referring to table (5) its remarkable that reducing mixing intensity increased the (OC) to about $63 \%$ and $61 \%$ at 5.35 and $10.7 \mathrm{~m}^{3} /$ day of air flowrate respectively, deducing that power saving in wastewater treatment plant may be accomplished by reducing the necessity to the high mixing intensities in the operation processes of the plant.

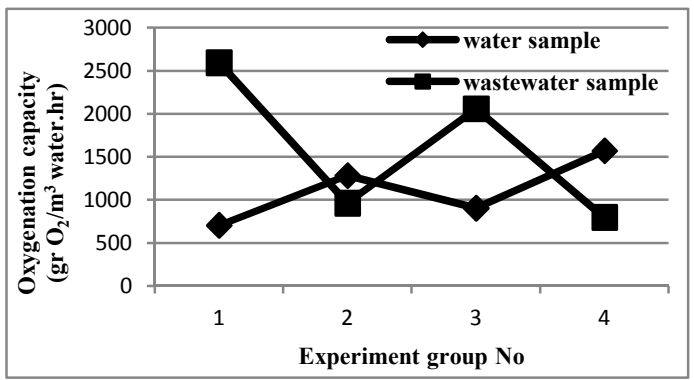

Fig. (5): Relationship between oxygenation capacity with mixing intensity and air flowrat 


\begin{tabular}{|c|c|c|c|c|}
\hline Parameter & $\begin{array}{c}\text { Q air }=5.3 \mathrm{~m}^{3} / \mathrm{d} \\
\mathrm{RPM}=50\end{array}$ & $\begin{array}{c}\text { Q air }=5.3 \mathrm{~m}^{3} / \mathrm{d} \\
\mathrm{RPM}=100\end{array}$ & $\begin{array}{c}\text { Q air }=10.7 \mathrm{~m}^{3} / \mathrm{d} \\
\mathrm{RPM}=50\end{array}$ & $\begin{array}{c}\text { Q air }=10.7 \mathrm{~m}^{3} / \mathrm{d} \\
\mathrm{RPM}=100\end{array}$ \\
\hline Alpha & $1.1 Y$ & 0.729 & 0.818 & 0.526 \\
\hline $\begin{array}{c}\text { OCWW } \\
\mathrm{mg} \mathrm{O}_{2} / 1 . \min \end{array}$ & 43.224 & 16.039 & 34.296 & 13.261 \\
\hline $\begin{array}{c}\mathrm{OCW} \\
\mathrm{mg} \mathrm{O}_{2} / 1 . \mathrm{min}\end{array}$ & 11.717 & 21.357 & 15.059 & 26.166 \\
\hline $\begin{array}{c}\text { KlaWW@20C } \\
1 / \mathrm{hr}\end{array}$ & 1.68 & 2.1 & 1.62 & 1.8 \\
\hline $\begin{array}{c}\mathrm{KLaW} @ 20^{\circ} \mathrm{C} \\
1 / \mathrm{hr} \\
\end{array}$ & 1.5 & 2.88 & 1.98 & 3.42 \\
\hline $\begin{array}{c}\text { Oxygenation } \\
\text { efficiency } \\
\text { of water } \% \\
\end{array}$ & 31.73 & 57.84 & 20.39 & 62.09 \\
\hline $\begin{array}{c}\text { Oxygenation } \\
\text { efficiency } \\
\text { of wastewater } \%\end{array}$ & 117 & 64.33 & 46.44 & 30.52 \\
\hline $\begin{array}{c}\text { Oxygen } \\
\text { absorption of } \\
\text { wastewater \% } \\
\end{array}$ & 1.17 & 1.44 & 0.56 & 0.59 \\
\hline $\begin{array}{c}\text { Oxygen } \\
\text { absorption of } \\
\text { water } \%\end{array}$ & 1.06 & 1.97 & 0.69 & 1.21 \\
\hline
\end{tabular}

Table. (5): Summary of The Results

In fig (6) the effect of sample type (wastewater, tap water) was obtained, since there was shortage in oxygen in waste sample due to degradation process the oxygen molecules was substituted rapidly. Group (1) indicated best result for oxygenation efficiency about 117 gr $\mathrm{O}_{2} / \mathrm{m}^{3}$ air assuring the needles to the high power for both mixing intensity ,air discharge .

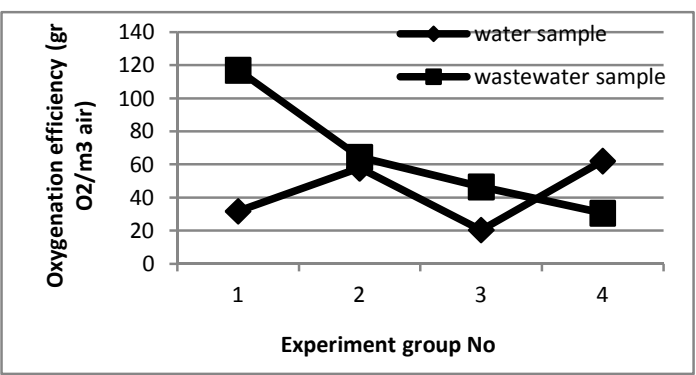

Fig. (6): Relationship between oxygenation efficiency with mixing intensity and air flowrate

For the oxygen absorption ratio related to experiment parameters in fig (7), it was unquestionable that the absorption ratio for wastewater was less than for tap water this may contributed to the resistance of wastewater sample to oxygen transmission to the bulk of the liquid by diffusion and convection.

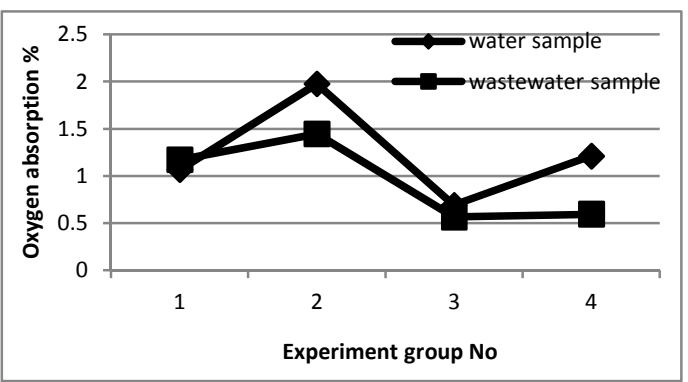

Fig. (7): Relationship between oxygen absorption with mixing intensity and air flowrate

\section{Conclusions:}

The use of hybrid aeration system in wastewater treatment was more efficient and economical in power saving than the conventional systems, since high values of oxygen transfer coefficients, oxygenation capacity and the correction factor of oxygen transfer were obtained at low mixing intensities and air flowrate of 50RPM and $5.35 \mathrm{~m}^{3} /$ day respectively.

\section{References}

Al-Ahmady, Kossy, K. (2006). "Analysis of Oxygen Transfer Performance on Subsurface Aeration Systems", Int. J. Environ. Res. Public Health, 3(3), pp. 301-308.

Bayramoglu, M., Ceakici, A. and Tekin, T. (2000). Modeling of Oxygen Transfer Rate in Diffused - Air Aeration Tanks", 
Institution of Chemical Engineers, Trans I Chem E, Vol. 78 ,Part B.

Chambers, B., Upton, J. and Greenhalgh, S.H. (1998). "The Development and Use of Hybrid Aeration Processes", J.CIWEM, 12.

Eckenfelder, J.W.W. (2000). "Industrial Water Pollution Control ", McGraw Hill International Edition.

German ATV Standards,(1996). Measurement of the Oxygen Transfer in Activated Sludge Aeration Tanks with Clean Water and in Mixed Liquor. pp. 1-54.

Kalinske A. A., Lash, L.D. and Shell, G.L. (1973). "Cobalt Interference in the Non-Steady State Clean Water Test", Water and Sewage Works, 120 (54).

Khudenko, B.M., Shpirt, E. (1986). "Hydrodynamic Parameters of Diffused Air Systems" Water Research, 20 (7).

Mark, R. (2005). "Design and Operation of Hybrid Aeration System " ,Siemens products SAWEA.

Metcalf, and Eddy, (2003). "Wastewater Engineering Treatment and Reuse", McGraw Hill companies Inc.4th Edition.

Pre-European, S. (1999). Wastewater treatment plant -part 15,"Mesurment of Oxygen Transfer in Clean Water in Activated Sludge Aeration Tank ", pp 1-16.
Ramalho, R.S. (1977). "Introduction to Wastewater Treatment Processes", Academic Press Inc., New York.

Shifrin, S.M., Mishukov, B.G. and Feofanov, E.A (1977). "Design of Biological Treatment Systems for Domestic and Industrial Wastewater", University Publishing House, Leningrad.

Smith, G. (2001). "Hybrid Aeration Process Provides Power Savings " ,Edition of Water Word

USEPA, 1989, "Design Manual - Fine Pore Aeration Systems", Center for Environmental Research, Cincinnati, Ohio.

Wagner, M. and Johannes, H. (1996). "Surface Active Agent And Their Influence On Oxygen Transfer ", water science and technology, Vol. 34,No 3-4, pp249-256.

Yannick, F., Arnaud, C., Sylvie, G., Michel, R., Alain, H. (2007). "Oxygen Transfer Prediction in Aeration Tanks Using CFD", Chemical Engineering Science 627163 7171.

Zhen, He, Anurak, P., Warawitya, M. (2003). "Oxygen Transfer Measurement in Clean Water " ,Journal of KMITNB ,Vol.13,No. 1.

كان الهدف من هذه الدراسة هو إستعر اض وتقييم فعالية نظام التهوية الهجين (المركب) ووصف آليات التشغيل المعتمدة في

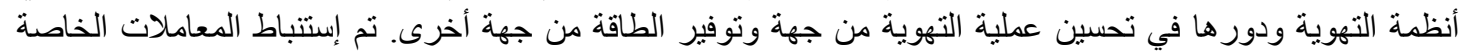

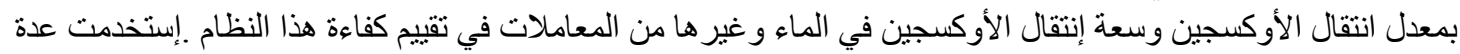

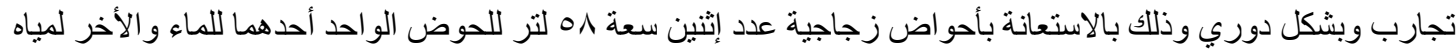
الفضلات المدنية حيث تم إجراء الفحوصات بشكل منواز للحوضين و عند فترات زمنية منساوية. تم در اسة تأثير كل من

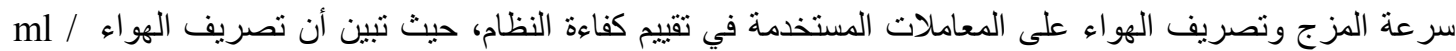

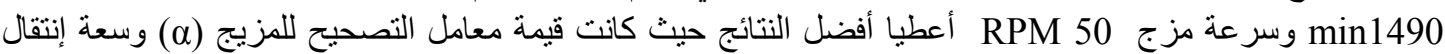

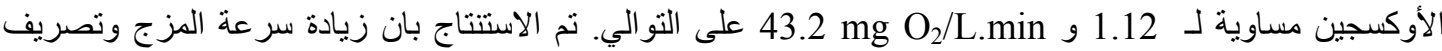
الهواء قد بؤثران بصورة سلبية على حجم الفقاعة وبالتالي على معدل إنتقال الأوكسجين في أنظمة التهوية في محطات معالجة مياه الفضلات. 